\title{
Glyphosate and AMPA inhibit cancer cell growth through inhibiting intracellular glycine synthesis
}

This article was published in the following Dove Press journal:

Drug Design, Development and Therapy

23 July 2013

Number of times this article has been viewed

\author{
Qingli $\mathrm{Li}^{1,2}$ \\ Mark J Lambrechts' \\ Qiuyang Zhang' \\ Sen Liu' \\ Dongxia $\mathrm{Ge}^{1}$ \\ Rutie Yin² \\ Mingrong $\mathrm{Xi}^{2}$ \\ Zongbing You'
}

'Departments of Structural and Cellular Biology and Orthopaedic Surgery, Tulane Cancer Center and Louisiana Cancer Research Consortium, Tulane Center for Stem Cell Research and Regenerative Medicine, and Tulane Center for Aging, Tulane University Health Sciences Center, New Orleans, LA, USA; ${ }^{2}$ Department of Obstetrics and Gynecology, West China Second University Hospital, Sichuan University, Chengdu, People's Republic of China
Correspondence: Zongbing You, Department of Structural and Cellular Biology, Tulane University, 1430 Tulane Ave SL 49, New Orleans, LA 70I I2, USA $\mathrm{Tel}+\mathrm{I} 5049880467$

Fax + I 5049881687

Email zyou@tulane.edu

\begin{abstract}
Glycine is a nonessential amino acid that is reversibly converted from serine intracellularly by serine hydroxymethyltransferase. Glyphosate and its degradation product, aminomethylphosphonic acid (AMPA), are analogs to glycine, thus they may inhibit serine hydroxymethyltransferase to decrease intracellular glycine synthesis. In this study, we found that glyphosate and AMPA inhibited cell growth in eight human cancer cell lines but not in two immortalized human normal prostatic epithelial cell lines. AMPA arrested C4-2B and PC-3 cancer cells in the G1/G0 phase and inhibited entry into the $\mathrm{S}$ phase of the cell cycle. AMPA also promoted apoptosis in C4-2B and PC-3 cancer cell lines. AMPA upregulated p53 and p21 protein levels as well as procaspase 9 protein levels in $\mathrm{C} 4-2 \mathrm{~B}$ cells, whereas it downregulated cyclin D3 protein levels. AMPA also activated caspase 3 and induced cleavage of poly (adenosine diphosphate $[\mathrm{ADP}]$-ribose) polymerase. This study provides the first evidence that glyphosate and AMPA can inhibit proliferation and promote apoptosis of cancer cells but not normal cells, suggesting that they have potentials to be developed into a new anticancer therapy.
\end{abstract}

Keywords: serine hydroxymethyltransferase, prostate cancer, apoptosis

\section{Introduction}

Glycine is a nonessential amino acid that can be converted directly from serine in mammalian cells. Serine is derived from 3-phosphoglycerate. Serine hydroxymethyltransferase (SHMT) reversibly catalyzes the conversion of serine to glycine and vice versa. In the liver of vertebrates, glycine can be synthesized from N5,N10-methylene tetrahydrofolate by glycine synthase. ${ }^{1}$ Glycine is the precursor material for biosynthesis of protein, purine, and glutathione. In addition, glycine is converted into sarcosine (N-methylglycine) by glycine N-methyltransferase, ${ }^{2}$ and reversely, sarcosine can be converted into glycine by sarcosine dehydrogenase. ${ }^{3}$ The serum half-life of intravenously administered glycine varies from $1 / 2$ hour to 4 hours. ${ }^{4}$ Recently, the importance of glycine in cancer cell biology has been revealed. ${ }^{5}$ In a human melanoma LOX IMVI cell line, about two-thirds of intracellular glycine is synthesized intracellularly, while one-third of intracellular glycine is taken from extracellular glycine sources. In a panel of 60 human cancer cell lines that the National Cancer Institute uses for anticancer drug screening, rapidly proliferating cancer cells consumed extracellular glycine due to increased demand for glycine. In contrast, rapidly proliferating human normal cell lines released glycine. ${ }^{5}$ These findings suggest that targeting glycine consumption may become a new strategy in killing rapidly proliferating cancer cells, while not harming rapidly proliferating normal cells. Indeed, the use of short hairpin RNA (shRNA) to knockdown expression of SHMT2, thus blocking endogenous glycine synthesis, 
effectively halted proliferation of LOX IMVI cells in the absence of extracellular glycine. In contrast, slowly proliferating cells were not affected by SHMT2 knockdown and deprivation of extracellular glycine. ${ }^{5}$

There are two isozymes of SHMT. SHMT1 encodes for the cytoplasmic and SHMT2 encodes for the mitochondrial isozyme. ${ }^{6-8}$ In mammalian cells, SHMT2 gene has an alternative promoter within intron 1, thus SHMT2 encodes for two transcripts, SHMT2 and SHMT2 $\alpha .{ }^{9}$ SHMT2 protein containing exon 1 (with mitochondrial-targeting sequence) is localized in mitochondria. SHMT2 $\alpha$ protein without exon 1 is not imported into mitochondria efficiently and is localized predominantly in the cytoplasm and nucleus. SHMT1 protein, like SHMT2 $\alpha$, is also localized in the cytoplasm and nucleus, and both SHMT1 and SHMT2 $\alpha$ catalyze production of one-carbon units from serine for nuclear de novo thymidylate biosynthesis. ${ }^{9}$ Interestingly, a glycine analog, aminomethylphosphonate (aminomethylphosphonic acid [AMPA]) (molecular formula $\mathrm{CH}_{6} \mathrm{NO}_{3} \mathrm{P}$ [Figure 1]), inhibits more than $95 \%$ of nuclear thymidylate biosynthesis that requires SHMT1 and SHMT2 $\alpha$, suggesting that AMPA is an effective inhibitor of SHMT1 and SHMT2 $\alpha$, as well as SHMT2. ${ }^{9}$

AMPA is the primary degradation product of glyphosate (N-(phosphonomethyl)glycine; molecular formula $\mathrm{C}_{3} \mathrm{H}_{3} \mathrm{NO}_{5} \mathrm{P}$ [Figure 1]). Glyphosate is water soluble and chemically stable and is degraded by microbes to produce AMPA. ${ }^{10}$ Glyphosate is a weak organic acid consisting of a glycine moiety and a phosphonomethyl moiety. Glyphosate is a broad-spectrum herbicide that is used worldwide in
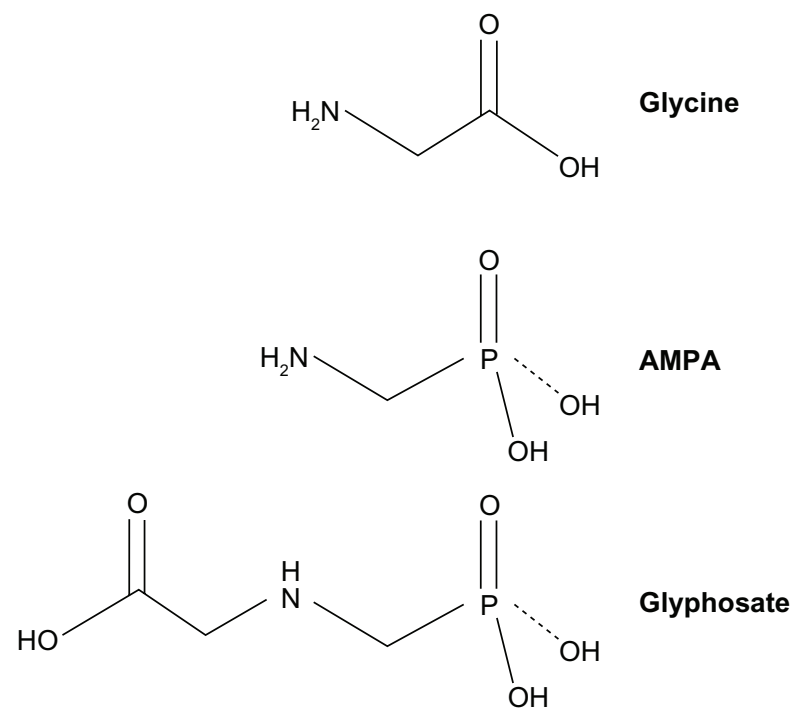

Figure I Chemical structure of glycine, AMPA, and glyphosate. Abbreviation: AMPA, aminomethylphosphonic acid. agriculture, forestry, and aquatic weed control. It is applied to many crops in various commercial formulations. The major formulation is Roundup ${ }^{\circledR}$ (Monsanto Co, St Louis, MO, USA), in which glyphosate is formulated as the isopropylamine salt, ${ }^{11}$ whereas AMPA has no commercial use. ${ }^{10}$ In animal studies using $\left[{ }^{14} \mathrm{C}\right]$ glyphosate in rats, rabbits, and goats, approximately $30 \%$ of the oral dose was absorbed through the gastrointestinal tract. On day 7 after the oral dose of $\left[{ }^{14} \mathrm{C}\right]$ glyphosate in rats, the isotope was distributed throughout the animal body, with the highest concentration found in the bones. Almost all of the isotope was eliminated in urine and feces, with a very low level exhaled in air. The only metabolite was AMPA, which accounted for about $0.2 \%$ to $0.3 \%$ of the administered dose of glyphosate. ${ }^{10}$ In a study in rats, approximately $20 \%$ of the oral dose of AMPA was absorbed, which was excreted almost exclusively through the urine, with less than $0.1 \%$ of the dose expired as $\mathrm{CO}_{2} \cdot{ }^{10} \mathrm{Gly}-$ phosate and AMPA have been found to present no significant toxicity in acute, subchronic, and chronic animal studies, nor any genotoxicity, teratogenicity, or carcinogenicity. ${ }^{10,12}$ In this study, we assessed the effects of glyphosate and AMPA on cancer cell growth. Our results suggest that glyphosate and AMPA inhibit cell growth in eight cancer cell lines but not in two immortalized human normal prostatic epithelial cell lines, at concentrations up to $50 \mathrm{mM}$.

\section{Materials and methods Cell culture}

The immortalized human normal prostatic epithelial cell lines RWPE-1 and pRNS-1-1 were obtained from Johng S Rhim (Uniformed Services University of the Health Sciences, Bethesda, MD, USA). ${ }^{13}$ Human castration-resistant prostate cancer cell line $\mathrm{C} 4-2 \mathrm{~B}$ was obtained from Leland WK Chung (Cedars-Sinai Medical Center, Los Angeles, CA, USA). ${ }^{14}$ Human prostate cancer cell lines (LNCaP, DU-145, and PC-3), human ovarian cancer cell lines (SKOV-3 and OVCAR-3), human cervical cancer HeLa cell line, and human lung cancer A549 cell line were purchased from the American Type Culture Collection (Manassas, VA, USA). RWPE-1 and pRNS-1-1 cells were cultured in Dulbecco's Modified Eagle's medium (DMEM) (Mediatech, Inc, Manassas, VA, USA) containing 10\% fetal bovine serum (FBS) (HyClone Standard Fetal Bovine Serum; Thermo Fisher Scientific Inc, Waltham, MA, USA), $100 \mathrm{IU} / \mathrm{mL}$ penicillin/streptomycin, $5 \mu \mathrm{g} / \mathrm{mL}$ bovine insulin, $25 \mu \mathrm{g} / \mathrm{mL}$ bovine pituitary extract, and $6 \mathrm{ng} / \mathrm{mL}$ recombinant human epidermal growth factor (Sigma-Aldrich Corp, St Louis, MO, USA). LNCaP cells were cultured in 
T-Medium (Life Technologies Corp, Carlsbad, CA, USA) containing 5\% FBS and $100 \mathrm{IU} / \mathrm{mL}$ penicillin/streptomycin. C4-2B and SKOV-3 cells were cultured in Roswell Park Memorial Institute (RPMI)-1640 medium (Thermo Fisher Scientific) containing 10\% FBS and $100 \mathrm{IU} / \mathrm{mL}$ penicillin/ streptomycin. OVCAR-3 cells were cultured in RPMI1640 medium containing 20\% FBS, $100 \mathrm{IU} / \mathrm{mL}$ penicillin/ streptomycin, $5 \mu \mathrm{g} / \mathrm{mL}$ bovine insulin, and $1 \mathrm{mM}$ sodium pyruvate. DU-145, PC-3, HeLa, and A549 cells were cultured in DMEM medium containing 10\% FBS and 100 $\mathrm{IU} / \mathrm{mL}$ penicillin/streptomycin. DMEM contains $30 \mathrm{mg} / \mathrm{L}$ glycine and $42 \mathrm{mg} / \mathrm{L}$ L-serine; RPMI-1640 medium contains $10 \mathrm{mg} / \mathrm{L}$ glycine and $30 \mathrm{mg} / \mathrm{L} \mathrm{L}$-serine; and T-Medium contains $27 \mathrm{mg} / \mathrm{L}$ glycine and $37.8 \mathrm{mg} / \mathrm{L} \mathrm{L}$-serine. The cells were cultured in a $5 \% \mathrm{CO}_{2}$ humidified incubator at $37^{\circ} \mathrm{C}$.

\section{Cell viability assay}

The live cell numbers were determined using the CellTiterGlo $^{\circledR}$ Luminescent Cell Viability Assay (Promega Corp, Fitchburg, WI, USA). This assay is based on quantitation of the adenosine triphosphate (ATP), an indicator of metabolically active cells, which is a well-established method for cell proliferation and cytotoxicity assays. ${ }^{15-17}$ To optimize the experimental conditions, we performed pilot experiments and determined that there was a linear relationship $\left(r^{2}=0.98\right)$ between the luminescent signal and the number of cells, from 1,000 to 40,000 cells per well. Therefore, we plated 4,000 cells per well, so that the cell number was less than 40,000 cells per well after 72 hours in culture. The cells were plated in $100 \mu \mathrm{L}$ complete culture medium with FBS in $\operatorname{Costar}^{\circledR}$ opaque-walled 96-well plates (Thermo Fisher Scientific Inc). After overnight incubation, the cells were treated with glyphosate or AMPA (Sigma-Aldrich Corp) at final concentrations of $0,15,25$, or $50 \mathrm{mM}$ for 72 hours. Both glyphosate and AMPA were used in their native forms in all the experiments, and they were dissolved in complete medium with FBS prior to use. Each treatment group had triplicate wells. Wells containing the same medium without cells were used to assess the background luminescence. The amount of $100 \mu \mathrm{L}$ CellTiter-Glo ${ }^{\circledR}$ Reagent was added into each well according to the instructions. Luminescence was read using a FLUOstar OPTIMA (BMG Labtech GmbH, Ortenberg, Germany) microplate reader. Cell viability was calculated as (luminescence of the treatment group background luminescence) $\div$ (luminescence of the control group - background luminescence) $\times 100 \%$. The data are presented as the mean and standard error of the mean (SEM) of three independent experiments.

\section{Cell cycle analysis}

C4-2B and PC-3 cells were plated in complete culture medium with FBS, into $60 \mathrm{~mm}$ dishes. After 16 hours, the cells were treated without or with AMPA at a final concentration of $50 \mathrm{mM}$ for 24 hours. The cells were trypsinized, washed once with phosphate buffered saline (PBS), pelleted, and resuspended in $70 \%$ ice-cold ethanol and stored at $-20^{\circ} \mathrm{C}$ until the cell cycle analysis. The fixed cells were stained in a solution containing $0.1 \%$ Triton $^{\mathrm{TM}} \mathrm{X}-100$ (Sigma-Aldrich Corp), $0.2 \mathrm{mg} / \mathrm{mL}$ DNase-free RNase A, and $20 \mu \mathrm{g} / \mathrm{mL}$ propidium iodide for $30 \mathrm{~min}$ at room temperature in the dark. The percentages of cells at $\mathrm{G} 1 / \mathrm{G} 0, \mathrm{~S}$, and $\mathrm{G} 2 / \mathrm{M}$ phases were determined by flow cytometry analysis using DNA content frequency histogram deconvolution software (Becton, Dickinson and Company, Franklin Lakes, NJ, USA).

\section{Cell apoptosis assay}

C4-2B and PC-3 cells were plated in complete culture medium with FBS into $60 \mathrm{~mm}$ dishes. Sixteen hours later, the cells were treated without or with AMPA at a final concentration of $50 \mathrm{mM}$ for $0,24,48$, and 72 hours. The cells were trypsinized, washed once with PBS, pelleted and resuspended in annexin-binding buffer. The cells were stained with Annexin-V Fluorescein isothiocyanate (FITC) Conjugate (1:20 dilution; Life Technologies Corp) and propidium iodide (100 $\mu \mathrm{g} / \mathrm{mL})$ according to the manufacturers protocol, and the percentages of apoptotic cells were determined by flow cytometry analysis. ${ }^{18,19}$

\section{Western blot analysis}

C4-2B cells were cultured in $60 \mathrm{~mm}$ dishes overnight. The cells were treated with AMPA at a final concentration of $50 \mathrm{mM}$ for $0,12,24,48$, and 72 hours. Proteins were extracted from the treated cells in radioimmunoprecipitation assay (RIPA) lysis buffer (50 mM sodium fluoride, $0.5 \%$ Igepal $^{\circledR}$ CA-630 [NP-40], $10 \mathrm{mM}$ sodium phosphate, $150 \mathrm{mM}$ sodium chloride, $25 \mathrm{mM}$ Tris $\mathrm{pH}$ 8.0, $1 \mathrm{mM}$ phenylmethylsulfonyl fluoride, $2 \mathrm{mM}$ ethylenediaminetetraacetic acid [EDTA], $1.2 \mathrm{mM}$ sodium vanadate) supplemented with protease inhibitor cocktail (Sigma-Aldrich Corp). An equal amount of proteins was subjected to $10 \%$ SDS-polyacrylamide gel electrophoresis and transferred to polyvinylidene difluoride membranes (Bio-Rad Laboratories, Hercules, CA, USA). The membranes were blocked with 5\% nonfat dry milk in TBST buffer ( $25 \mathrm{mM}$ Tris-HCl, $125 \mathrm{mM} \mathrm{NaCl}, 0.1 \%$ Tween 20 ) for 2 hours and probed with the indicated primary antibodies overnight and then IRDye ${ }^{\circledR} 800 \mathrm{CW}$ - or IRDye ${ }^{\circledR} 680$-conjugated secondary antibodies (LI-COR Biosciences Inc, Lincoln, 
NE, USA) for 1 hour. The results were visualized using an Odyssey ${ }^{\circledR}$ Infrared Imager (LI-COR Biosciences Inc). For loading control, the membranes were stripped and probed for glyceraldehyde-3-phosphate dehydrogenase (GAPDH). The antibodies used were as follows: rabbit anti-poly (adenosine diphosphate [ADP]-ribose) polymerase (PARP), rabbit anticaspase 3, rabbit anti-caspase 9, and mouse anti-cyclin D3 antibodies, purchased from Cell Signaling Technology Inc (Danvers, MA, USA); mouse anti-p21 and goat anti-p53 antibodies, obtained from Santa Cruz Biotechnology Inc (Dallas, TX, USA); and mouse anti-GAPDH antibodies, ordered from EMD Millipore Corp (Billerica, MA, USA).

\section{Statistical analysis}

All experiments were repeated three times, and the results represent mean \pm SEM of three independent experiments. Statistical analysis was made using two-tailed Student's $t$ test. A $P$-value $<0.05$ was considered statistically significant.

\section{Results}

\section{Glyphosate inhibits cell growth in cancer cell lines but not in normal cell lines}

Glyphosate, at concentrations of 15,25 , and $50 \mathrm{mM}$, did not significantly decrease the cell viability in the RWPE-1 and pRNS-1-1 cell lines compared with the untreated control group $(P>0.05)$ (Figure 2A and B). Glyphosate, at concentrations of 15 and $25 \mathrm{mM}$, did not decrease the cell viability in the LNCaP cell line; however, it decreased $27 \%$ of the cell viability at a concentration of $50 \mathrm{mM}(P<0.05)$ (Figure $2 \mathrm{C})$. Glyphosate, at concentrations of 15,25 , and $50 \mathrm{mM}$, significantly decreased the cell viability in the C4-2B and DU-145 cell lines $(P<0.05$ or $P<0.01)$ (Figure $2 \mathrm{D}$ and $\mathrm{E})$, with a $73.4 \%$ and $39.3 \%$ decrease at the dose of $50 \mathrm{mM}$, respectively. Glyphosate, at a concentration of $15 \mathrm{mM}$, did not decrease the cell viability in the PC-3 and SKOV-3 cell lines; however, it significantly decreased the cell viability at concentrations of 25 and $50 \mathrm{mM}(P<0.05$ or $P<0.01)$ (Figure $2 \mathrm{~F}$ and $\mathrm{G})$, with a $36.9 \%$ and $28 \%$ decrease at the dose of $50 \mathrm{mM}$ in the PC-3 and SKOV-3 cell lines, respectively. Glyphosate, at concentrations of 15,25 , and $50 \mathrm{mM}$, significantly decreased the cell viability in the OVCAR-3 cell line $(P<0.05$ or $P<0.01$ ) (Figure $2 \mathrm{H}$ ), with a $58.8 \%$ decrease at the dose of $50 \mathrm{mM}$. However, at a concentration of $50 \mathrm{mM}$, glyphosate only decreased about $25 \%$ and $17 \%$ of the cell viability in the HeLa and A549 cell lines, respectively, though the decrease was statistically significant $(P<0.05)$ (Figure 2I and J). Based on the percentages of inhibition caused by different concentrations of glyphosate, we estimated the half maximal $(50 \%)$ inhibitory concentrations $\left(\mathrm{IC}_{50}\right)$ of glyphosate in the cell lines, using a linear regression model (Table 1).

\section{AMPA inhibits cell growth in cancer cell lines but not in normal cell lines}

AMPA, at concentrations of 15,25 , and $50 \mathrm{mM}$, did not significantly decrease the cell viability in the RWPE-1 and pRNS-1-1 cell lines $(P>0.05)$ (Figure $3 \mathrm{~A}$ and $\mathrm{B})$. In contrast, AMPA, at concentrations of 25 and $50 \mathrm{mM}$, significantly decreased the cell viability in the LNCaP, DU-145, SKOV-3, HeLa, and A549 cell lines $(P<0.05$ or $P<0.01)$ (Figure $3 \mathrm{C}$, E, G, I and J), while AMPA at concentrations of 15, 25, and $50 \mathrm{mM}$ significantly decreased the cell viability in the $\mathrm{C} 4-2 \mathrm{~B}$, PC-3, and OVCAR-3 cell lines $(P<0.05$ or $P<0.01)$ (Figure $3 \mathrm{D}, \mathrm{F}$ and $\mathrm{H})$. The percentages of decrease in cell viability at $50 \mathrm{mM}$ AMPA were $32 \%$ in LNCaP, $54.5 \%$ in $\mathrm{C} 4-2 \mathrm{~B}, 47 \%$ in DU-145, 41.7\% in PC-3, 28.5\% in SKOV-3, 33.6\% in OVCAR-3, 25\% in HeLa, and 31.4\% in the A549 cell lines. Of note, we found that at a concentration of $100 \mathrm{mM}$, AMPA decreased the cell viability in the RWPE- 1 and pRNS-1-1 cell lines by $59.5 \%$ and $57.6 \%$, respectively. In contrast, this high concentration of AMPA decreased cell viability by $54 \%$ in LNCaP, 91\% in C4-2B, 67\% in DU-145, 85.1\% in PC-3, 42\% in SKOV-3, 79.9\% in OVCAR-3, 50.6\% in HeLa, and 53.1\% in the A549 cell lines. The $\mathrm{IC}_{50}$ concentrations of AMPA in inhibition of the cell growth in the normal and cancer cell lines are shown in Table 1.

\section{AMPA inhibits entry into the $S$ phase of cell cycle and increases apoptosis}

AMPA, at a concentration of $50 \mathrm{mM}$, significantly increased the number of C4-2B and PC-3 cells in the G1/G0 phase of cell cycle, compared with the control group $(P<0.05$ or $P<0.01$ ) (Figure 4A and B). In contrast, AMPA significantly decreased the number of $\mathrm{C} 4-2 \mathrm{~B}$ and $\mathrm{PC}-3$ cells in the $\mathrm{S}$ phase of cell cycle $(P<0.05$ or $P<0.01)$, whereas the number of cells in the G2/M phase was not affected (Figure 4A and B). In addition, AMPA, at a concentration of $50 \mathrm{mM}$, significantly increased apoptosis of C4-2B and PC-3 cells in a timedependent manner $(P<0.01)$ (Figure $4 \mathrm{C}$ and $\mathrm{D})$.

\section{AMPA induces changes in expression levels of genes involved in cell cycle and apoptosis}

AMPA, at a concentration of $50 \mathrm{mM}$, increased the levels of cleaved PARP in the C4-2B cells in a time-dependent 
A

RWPE-1 B

pRNS-1-1

C

LNCaP

C4-2B

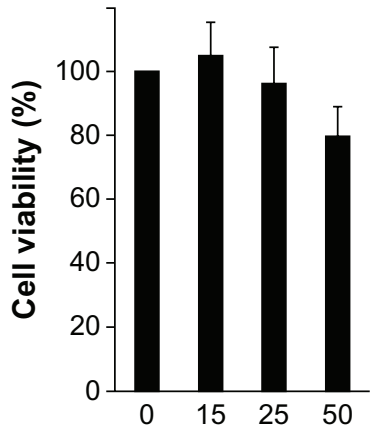

Glyphosate (mM)

E

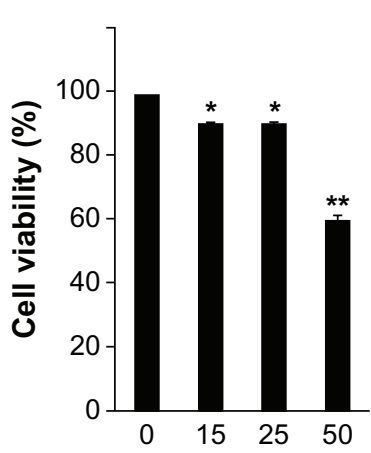

Glyphosate (mM)

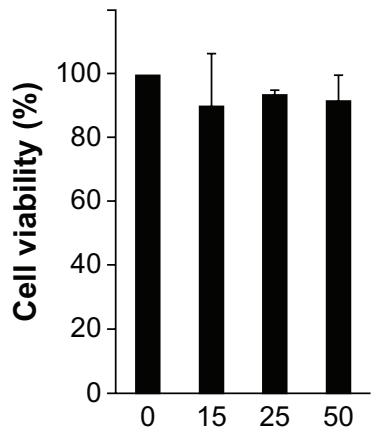

Glyphosate (mM)

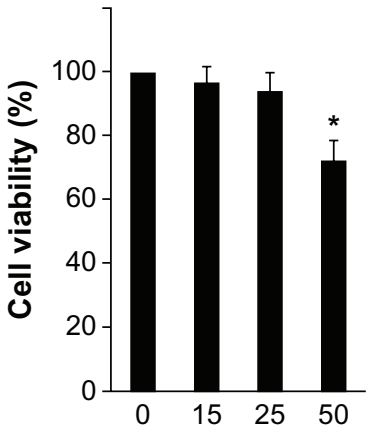

Glyphosate (mM)

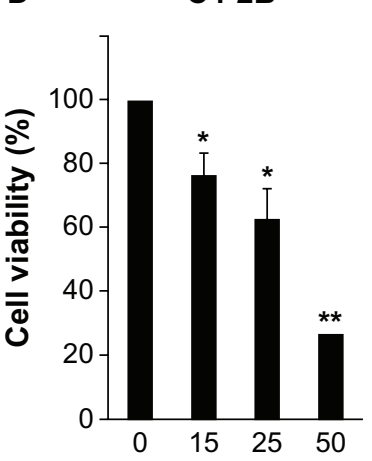

Glyphosate (mM)

$\mathbf{F}$

PC-3

G

SKOV-3

H

OVCAR-3

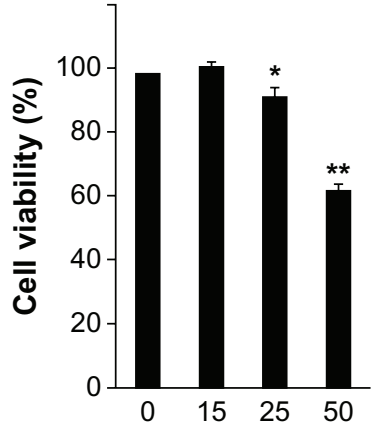

Glyphosate (mM)

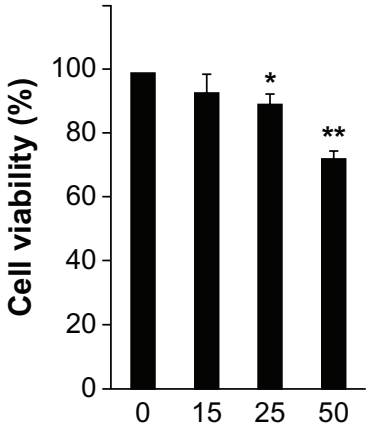

Glyphosate (mM)

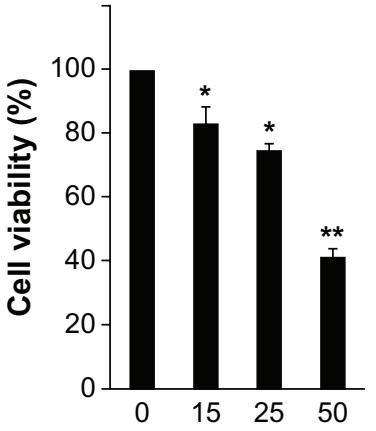

Glyphosate (mM)

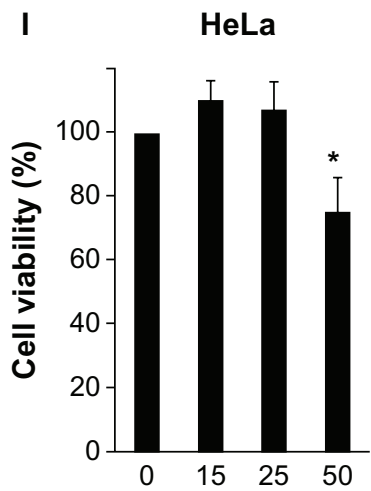

Glyphosate (mM)
J

A549

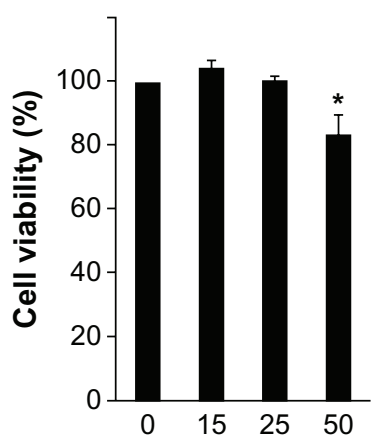

Glyphosate (mM)

Figure 2 Glyphosate inhibits cell growth in cancer cell lines but not in normal cell lines.

Notes: (A-J) The cells were treated with $0,15,25$, and $50 \mathrm{mM}$ of glyphosate for 72 hours. Cell viability was determined using CellTiter-Glo ${ }^{\circledR}$ Luminescent Cell Viability Assay. Data represent the mean \pm SEM obtained from three independent experiments. $* P<0.05$ and $* * P<0.0$ I, compared with the untreated control group. Abbreviation: SEM, standard error of the mean.

Table I Half maximal inhibitory concentrations $\left(\mathrm{IC}_{50}\right)$ of glyphosate and AMPA in inhibition of the cell growth in the normal and cancer cell lines

\begin{tabular}{|c|c|c|c|c|c|c|c|c|c|c|}
\hline Cell line & RWPE-I & pRNS-I - I & LNCaP & C4-2B & DU-I 45 & PC-3 & SKOV-3 & OVCAR-3 & HeLa & A549 \\
\hline Glyphosate & 109.1 & 372.8 & 90.4 & 34.2 & 63.9 & 63.2 & 89.0 & 42.7 & 89.4 & 136.7 \\
\hline AMPA & 88.3 & 90.9 & 93.1 & 59.8 & 68.1 & 58.6 & 127.1 & 62.8 & 99.9 & 98.2 \\
\hline
\end{tabular}

Note: Values are expressed in $\mathrm{mM}$.

Abbreviation: AMPA, aminomethylphosphonic acid. 

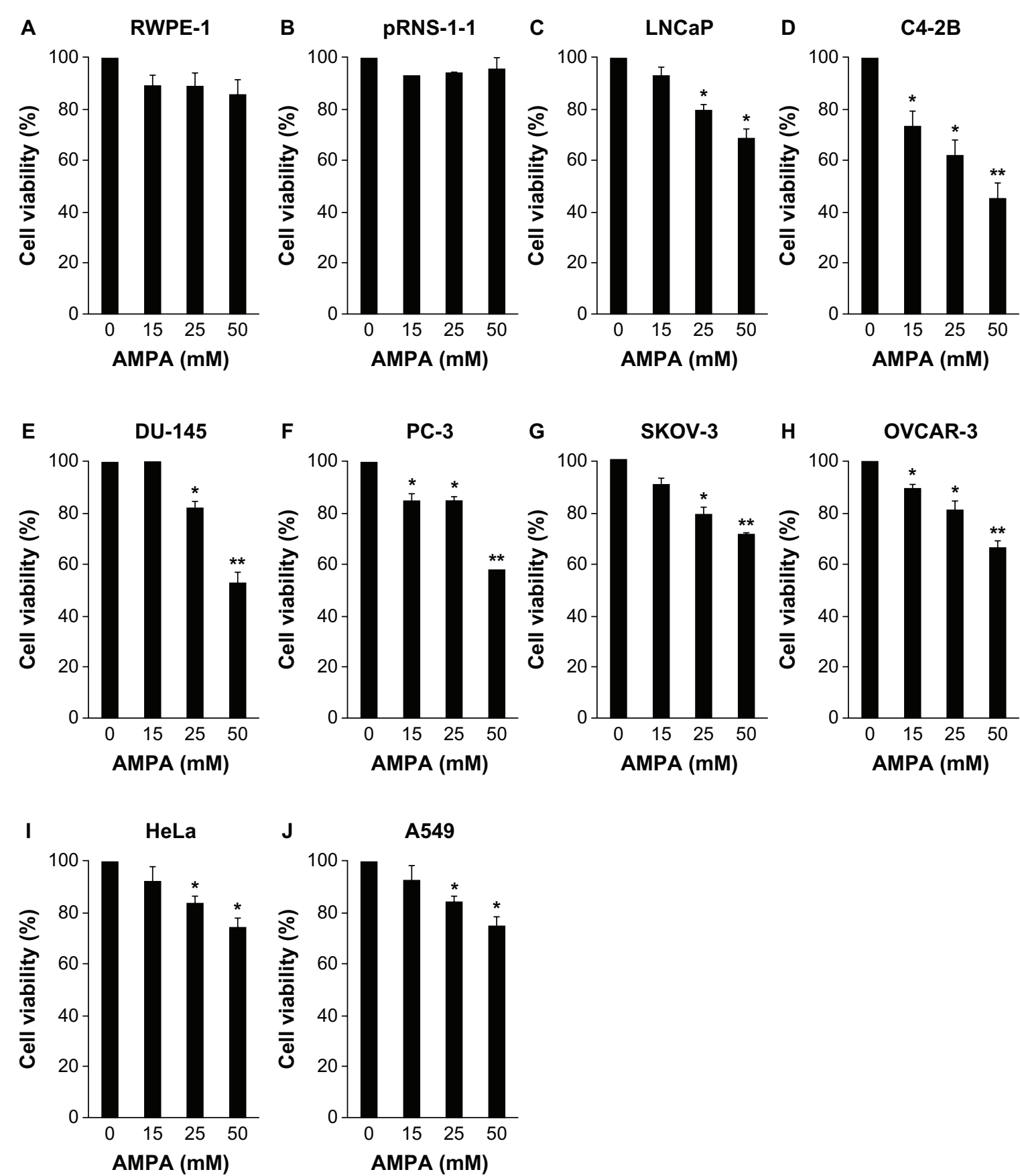

Figure 3 AMPA inhibits cell growth in cancer cell lines but not in normal cell lines.

Notes: (A-J) The cells were treated with 0, 15, 25, and 50 mM of AMPA for 72 hours. Cell viability was determined using CellTiter-Glo ${ }^{\circledR}$ Luminescent Cell Viability Assay. Data represent the mean \pm SEM obtained from three independent experiments. $* P<0.05$ and $* * P<0.0$ l, compared with the untreated control group.

Abbreviations: AMPA, aminomethylphosphonic acid; SEM, standard error of the mean.

manner (Figure 5A). AMPA transiently increased the levels of p53 and its downstream gene p21, at 12 hours after treatment (Figure 5B). It also decreased cyclin D3 protein levels, starting from 12 hours after treatment (Figure 5B). Further, AMPA increased the levels of procaspase 9, starting from 24 hours after treatment (Figure 5B). In contrast, AMPA decreased the levels of procaspase 3 , starting from 24 hours after treatment (Figure 5B).

\section{Discussion}

A previous study identified glycine as being consumed by rapidly proliferating cancer cell lines. Among the 60 human cancer cell lines tested in the previous study, five were included in the present study, namely, DU-145, PC-3, SKOV-3, OVCAR-3, and A549. Previously, it was shown that cancer cell proliferation was impaired by knocking down the expression levels of SHMT2 that is responsible 
A

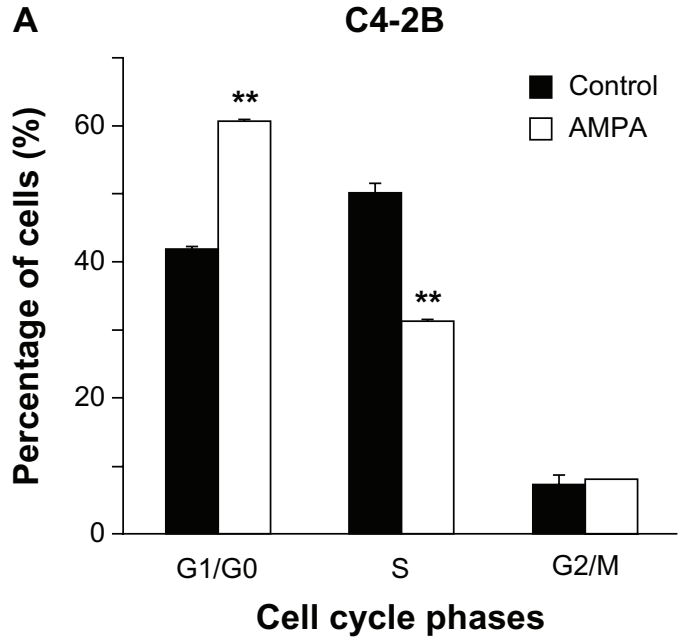

C

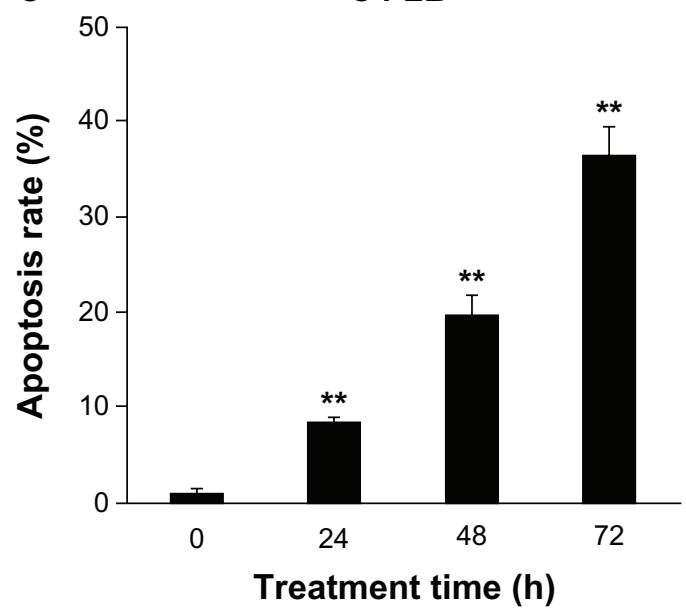

B

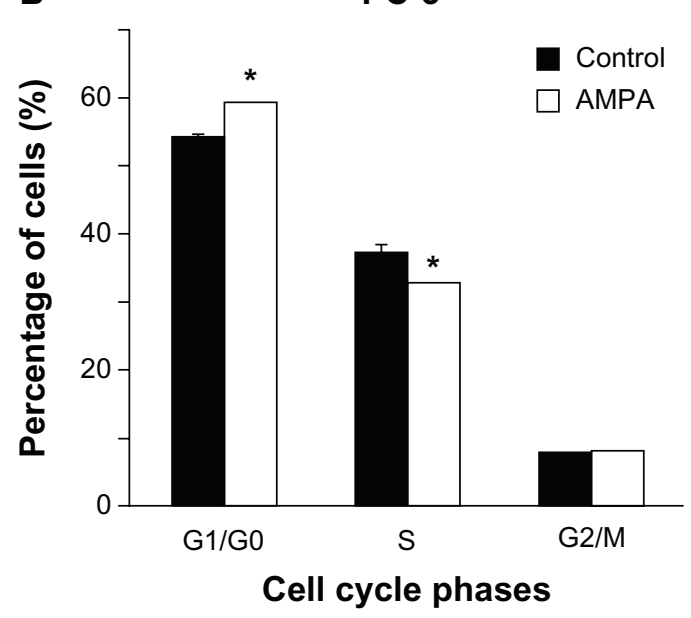

D

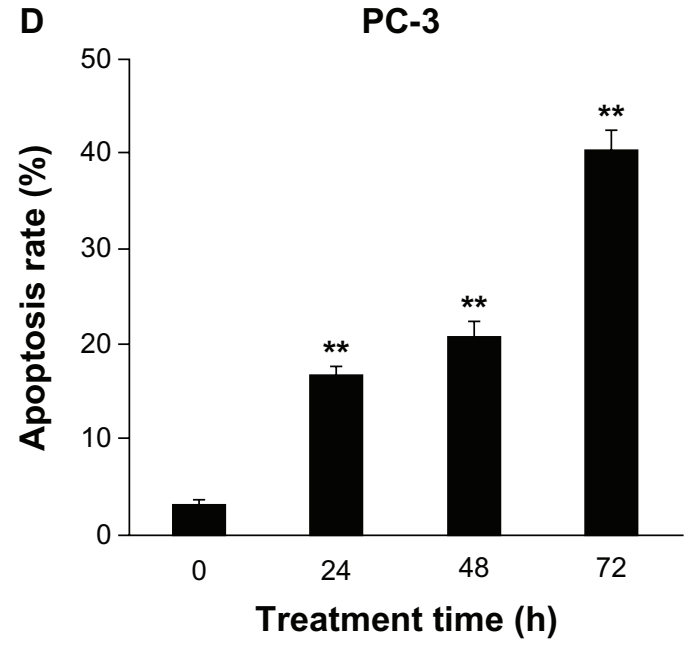

Figure 4 AMPA inhibits entry into the $S$ phase of cell cycle and increases apoptosis.

Notes: C4-2B and PC-3 cells were treated with or without 50 mM AMPA for 24 hours (A and B) or 0, 24, 48, and 72 hours (h) (C and D). Percentages of the cells in GI/G0, $\mathrm{S}$, and G2/M phases of cell cycle were determined using propidium iodide staining and flow cytometry analysis (A and $\mathbf{B})$. Apoptosis rates were determined using Annexin- $V$ FITC Conjugate and propidium iodide double staining and flow cytometry analysis (C and $\mathbf{D})$. Data represent the mean \pm SEM obtained from three independent experiments. $* P<0.05$ and $* * P<0.01$, compared with the control group.

Abbreviations: AMPA, aminomethylphosphonic acid; FITC, Fluorescein isothiocyanate; SEM, standard error of the mean.

for intracellular glycine synthesis. ${ }^{5}$ Here we present data showing that glycine analogs, glyphosate and AMPA, inhibited cell growth in eight cancer cell lines, including four human prostate cancer cell lines (LNCaP, C4-2B, DU-145, and PC-3), two human ovarian cancer cell lines (SKOV-3 and OVCAR-3), one human cervical cancer cell line (HeLa), and one human lung cancer cell line (A549). In contrast, glyphosate and AMPA did not impair the growth of two immortalized human normal prostatic epithelial cell lines (RWPE-1 and pRNS-1-1) at concentrations up to $50 \mathrm{mM}$. These findings suggest that glyphosate and AMPA can differentially affect cancer cell growth but not normal cell growth at concentrations up to $50 \mathrm{mM}$. However, at a higher concentration of $100 \mathrm{mM}$, AMPA decreased cell viability of the two normal cell lines, suggesting that potential adverse side effects may arise when the doses are too high. A safe therapeutic window may be limited to a drug concentration of between $50 \mathrm{mM}$ to $100 \mathrm{mM}$. However, in clinical practice, it may be difficult to administer the drugs to reach this high concentration. Therefore, the use of glyphosate and AMPA in patients may be limited if the high $\mathrm{IC}_{50}$ concentrations are difficult to achieve in patients' blood. Nevertheless, glyphosate, particularly AMPA, may be a good lead compound for developing more potent inhibitors with low $\mathrm{IC}_{50}$ concentrations.

Among the human cancer cell lines, the castrationresistant prostate cancer cell lines (C4-2B, DU-145, and PC-3) and ovarian cancer cell line (OVCAR-3) appear to be 
A
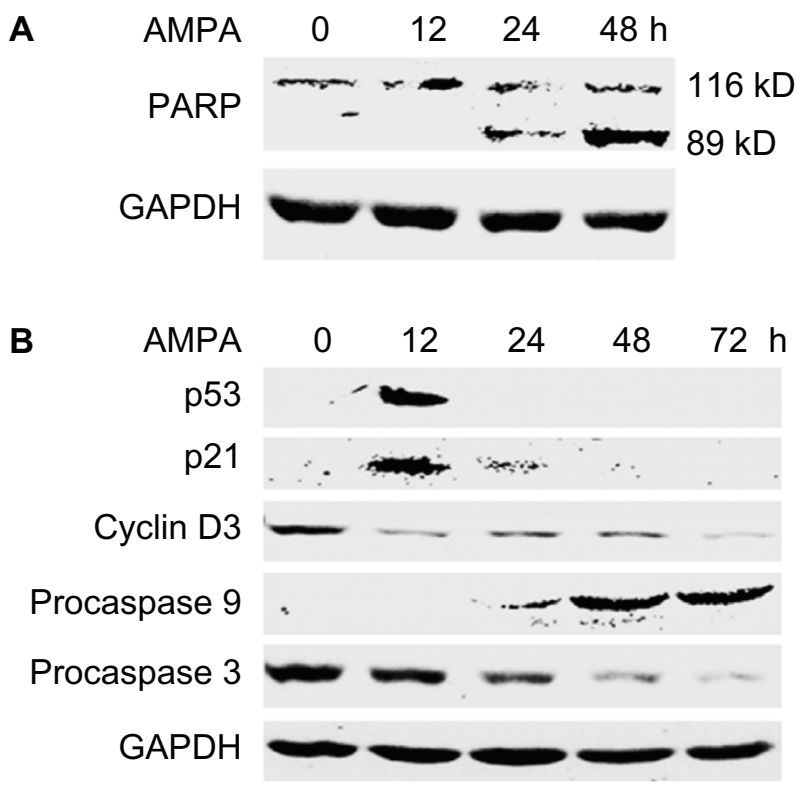

Figure 5 AMPA induces changes in expression levels of genes involved in cell cycle and apoptosis.

Notes: (A-B) C4-2B cells were treated with 50 mM AMPA for the indicated time. Western blot analysis was performed to determine the protein levels. For loading control, the blots were stripped and probed for GAPDH. For PARP, the II6-kD band is the full length, and the $89-\mathrm{kD}$ band is the cleaved form.

Abbreviations: AMPA, aminomethylphosphonic acid; GAPDH, glyceraldehyde3-phosphate dehydrogenase; h, hours; PARP, poly(ADP-ribose) polymerase; ADP, adenosine diphosphate.

more sensitive to glyphosate and AMPA than are the other human cancer cell lines. The $\mathrm{IC}_{50}$ concentrations varied from 34.2 to $68.1 \mathrm{mM}$ among the four sensitive cancer cell lines (C4-2B, DU-145, PC-3, and OVCAR-3). In contrast, the $\mathrm{IC}_{50}$ concentrations were between 89 and $136.7 \mathrm{mM}$ in other cancer cell lines, including LNCaP, SKOV-3, HeLa, and A549 (Table 1), suggesting that these four cell lines are resistant to glyphosate and AMPA. The differences in sensitivity may be caused by many factors that are not clearly understood because these cell lines are derived from different genetic backgrounds. The rate of cell proliferation may be one of the factors, as suggested by previous study. ${ }^{5}$ Indeed, the $\mathrm{C} 4-2 \mathrm{~B}$ cells were more sensitive to glyphosate and AMPA than LNCaP cells. Coincidentally, LNCaP cells grow slower than $\mathrm{C} 4-2 \mathrm{~B}$ cells, which are castration-resistant cells derived from the hormone-sensitive LNCaP cells. ${ }^{14}$ This observation indicates that glyphosate and AMPA are more effective in inhibiting growth of rapidly proliferating cancer cells.

Cell growth in a population of cells represents the net outcome of proliferation and apoptosis. Our data indicate that AMPA can arrest cancer cells in the G1/G0 phase of cell cycle, thus inhibiting entry into the $\mathrm{S}$ phase. On the other hand, AMPA can enhance apoptosis of cancer cells, as shown by the increased rates of annexin- $\mathrm{V}$-positive cells and increased levels of cleaved PARP, an indicator of apoptosis. Therefore, AMPA inhibits cancer cell growth through inhibition of cellular proliferation and promotion of apoptosis. The molecular mechanism may be that AMPA upregulates the p53 protein level, which subsequently increases p21 protein level. Activation of the p53-p21 pathway is known to cause G1-phase arrest and apoptosis in mammalian cells. ${ }^{20-22}$ AMPA downregulates the expression of cyclin D3, which may also contribute to the cell cycle arrest. ${ }^{23}$ AMPA increases procaspase 9 levels and simultaneously decreases procaspase 3 levels, which may mediate apoptosis, as shown in a previous study. ${ }^{24}$ However, how AMPA initiates these molecular changes and whether these changes apply to other cancer cell lines remain to be determined.

To our best knowledge, this is the first study showing that glycine analogs can inhibit proliferation and promote apoptosis of cancer cells but not normal cells, in vitro at concentrations up to $50 \mathrm{mM}$. Higher concentrations of the chemicals may affect normal cells, thus producing adverse side effects. These findings suggest that animal studies are warranted to assess the efficacy of glyphosate and AMPA in the treatment of tumors growing in animals and to test whether the effective inhibitory concentrations can be achieved in animal blood. If a positive outcome is obtained in preclinical animal study, it will be feasible to conduct human clinical trials because glyphosate and AMPA are of little toxicity to animals and humans. ${ }^{10}$ On the other hand, more potent inhibitors may be developed using glyphosate and AMPA as lead compounds. Based on our findings and the previous report, ${ }^{5}$ it appears promising to develop a new anticancer therapy targeting glycine metabolism.

\section{Acknowledgments}

This work was partly supported by a grant from the Department of Defense (PC121647), two grants from the National Institute of General Medical Sciences (P20GM103518) and the National Cancer Institute (R01CA174714) of the National Institutes of Health, the Developmental Fund of Tulane Cancer Center (TCC), and the Louisiana Cancer Research Consortium (LCRC) Fund (to ZY). Dr Zongbing You conceived the idea and designed the experiments. The content of this article is solely the responsibility of the authors and does not necessarily represent the official views of the National Institutes of Health. The TCC and LCRC FACS Core Facilities were used to conduct this study. Dr Qingli Li received a scholarship from the State Scholarship Fund via China Scholarship Council (CSC) for her training under Dr Zongbing You at Tulane University. 


\section{Disclosure}

The authors report no conflicts of interest in this work.

\section{References}

1. Nelson DL, Cox MM. 2008. Principles of Biochemistry. New York, NY: WH Freeman and Company; 2008.

2. Kerr SJ. Competing methyltransferase systems. J Biol Chem. 1972;247(13):4248-4252.

3. Porter DH, Cook RJ, Wagner C. Enzymatic properties of dimethylglycine dehydrogenase and sarcosine dehydrogenase from rat liver. Arch Biochem Biophys. 1985;243(2):396-407.

4. Hahn RG. Dose-dependent half-life of glycine. Urol Res. 1993;21(4): 289-291.

5. Jain M, Nilsson R, Sharma S, et al. Metabolite profiling identifies a key role for glycine in rapid cancer cell proliferation. Science. 2012;336(6084):1040-1044.

6. Garrow TA, Brenner AA, Whitehead VM, et al. Cloning of human cDNAs encoding mitochondrial and cytosolic serine hydroxymethyltransferases and chromosomal localization. J Biol Chem. 1993;268(16): 11910-11916.

7. Girgis S, Nasrallah IM, Suh JR, et al. Molecular cloning, characterization and alternative splicing of the human cytoplasmic serine hydroxymethyltransferase gene. Gene. 1998;210(2):315-324.

8. Stover PJ, Chen LH, Suh JR, Stover DM, Keyomarsi K, Shane B. Molecular cloning, characterization, and regulation of the human mitochondrial serine hydroxymethyltransferase gene. J Biol Chem. 1997;272(3):1842-1848.

9. Anderson DD, Stover PJ. SHMT1 and SHMT2 are functionally redundant in nuclear de novo thymidylate biosynthesis. PLoS One. 2009;4(6):e5839.

10. World Health Organization (WHO). Glyphosate and AMPA in DrinkingWater. Background Document for Development of WHO Guidelines for Drinking-Water Quality. Geneva: WHO; 2005.

11. World Health Organization (WHO). IPCS, Environmental Health Criteria 159: Glyphosate. Geneva: WHO; 1994.

12. Williams GM, Kroes R, Munro IC. Safety evaluation and risk assessment of the herbicide Roundup and its active ingredient, glyphosate, for humans. Regul Toxicol Pharmacol. 2000;31(2 Pt 1):117-165.
13. You Z, Dong Y, Kong X, Zhang Y, Vessella RL, Melamed J. Differential expression of IL-17RC isoforms in androgen-dependent and androgenindependent prostate cancers. Neoplasia. 2007;9(6):464-470.

14. Thalmann GN, Sikes RA, Wu TT, et al. LNCaP progression model of human prostate cancer: androgen-independence and osseous metastasis. Prostate. 2000;44(2):91-103.

15. Crouch SP, Kozlowski R, Slater KJ, Fletcher J. The use of ATP bioluminescence as a measure of cell proliferation and cytotoxicity. J Immunol Methods. 1993;160(1):81-88.

16. Kangas L, Grönroos M, Nieminen AL. Bioluminescence of cellular ATP: a new method for evaluating cytotoxic agents in vitro. Med Biol. 1984;62(6):338-343.

17. Elisia I, Popovich DG, Hu C, Kitts DD. Evaluation of viability assays for anthocyanins in cultured cells. Phytochem Anal. 2008;19(6): 479-486.

18. Vermes I, Haanen C, Steffens-Nakken H, Reutelingsperger C. A novel assay for apoptosis. Flow cytometric detection of phosphatidylserine expression on early apoptotic cells using fluorescein labelled Annexin V. J Immunol Methods. 1995;184(1):39-51.

19. Mead RN, Ryu J, Liu S, et al. Supraphysiologic temperature enhances cytotoxic effects of bupivacaine on bovine articular chondrocytes in an in vitro study. Arthroscopy. 2012;28(3):397-404.

20. He G, Siddik ZH, Huang Z, et al. Induction of $\mathrm{p} 21$ by p53 following DNA damage inhibits both Cdk4 and Cdk2 activities. Oncogene. 2005;24(18):2929-2943.

21. el-Deiry WS, Harper JW, O'Connor PM, et al. WAF1/CIP1 is induced in p53-mediated G1 arrest and apoptosis. Cancer Res. 1994;54(5): 1169-1174.

22. el-Deiry WS, Tokino T, Velculescu VE, et al. WAF1, a potential mediator of p53 tumor suppression. Cell. 1993;75(4):817-825.

23. Fimognari C, Nusse M, Berti F, Iori R, Cantelli-Forti G, Hrelia P. Cyclin D3 and p53 mediate sulforaphane-induced cell cycle delay and apoptosis in non-transformed human T lymphocytes. Cell Mol Life Sci. 2002;59(11):2004-2012.

24. Sakai T, Liu L, Teng X, et al. Nucling recruits Apaf-1/pro-caspase-9 complex for the induction of stress-induced apoptosis. J Biol Chem. 2004;279(39):41131-41140.

\section{Publish your work in this journal}

Drug Design, Development and Therapy is an international, peerreviewed open-access journal that spans the spectrum of drug design and development through to clinical applications. Clinical outcomes, patient safety, and programs for the development and effective, safe, and sustained use of medicines are a feature of the journal, which

\section{Dovepress}

has also been accepted for indexing on PubMed Central. The manuscript management system is completely online and includes a very quick and fair peer-review system, which is all easy to use. Visit http://www.dovepress.com/testimonials.php to read real quotes from published authors. 